\title{
Early Repair of Traumatic Rupture of the Thoracic Aorta
}

\author{
L. L. BROMLEY,* .M.CHIR., F.R.C.S. ; J. T. HOBBS, *†.M.D., F.R.C.S. ; R. E. ROBINSON, $\dagger$ M.B., F.R.C.S.
}

Brit. med. F., 1965, 2, 17-19

Rupture of the thoracic aorta due to the trauma of abrupt deceleration is becoming more common in this age of high-speed travel and collision. The clinical picture of the torn aorta may not be recognized during life as it is not generally realized that it can occur without evidence of external injury to the chest.

The injury is closed, rupture usually occurring just distal to the ligamentum arteriosum, this site being the junction of the descending aorta, which is relatively fixed by the paired intercostal vessels, and the arch of the aorta, which is only suspended by the head vessels and which moves forward on impact with a severe shearing strain. One of three things can happen: the aorta may be completely divided and the overlying parietal pleura torn, with immediate exsanguination into the mediastinum and left pleural cavity; secondly, although rupture of the intima and media is complete, the adventitia may be incompletely disrupted, and this, together with the intact parietal pleura, temporarily contains the expanding aneurysm, which may, within minutes or hours, burst into the pleural cavity; and, finally, the remaining adventitia and pleura can succeed in containing the aneurysm, so that a localized aneurysmal sac develops which slowly expands until it ruptures. In those patients surviving for a short time it is not possible to know whether rupture is imminent, but evidence of continued internal haemorrhage, an expanding mediastinal shadow on $x$-ray examination, and an increasing pleural effusion are signs that early rupture is probable, and surgical treatment should be immediately undertaken.

Strassmann (1947) reviewed 7,000 necropsies performed during six years (1936-42) in Manhattan and reported 72 cases of traumatic aortic rupture, 42 of which occurred in young people without evidence of pathological change in the aorta. The most frequent site of rupture was at the aortic isthmus below the origin of the left subclavian artery, and the tear was usually transverse. In 59 patients death occurred within one hour of injury, the rupture extending through all layers; nine patients lived from one to seven hours and four from 12 to 18 hours; in eight of the late deaths the adventitia had remained intact. Eiseman and Rainer (1958) reported six cases of ruptured aorta and described the natural history. Four of their cases were diagnosed three and a half to four years after injury, but one case was diagnosed at 16 hours and an unsuccessful operation was performed at 40 days.

Since $80 \%$ of cases of traumatic aortic rupture survive for at least one hour (Strassmann, 1947), and yet only $3 \%$ of these patients are alive after two weeks (Parmley et al., 1958), early surgical intervention is essential. In the series of seven patients reported by Spencer et al. (1961) only one was diagnosed immediately, and six died after intervals of 4, 12, 14, 24 hours, 4 days, and 3 weeks respectively. McBurney and Vaughan's (1961) series of six cases all survived over eight hours and yet only: one was diagnosed immediately; the other five died at intervals of $10,14,24,36$ hours, and 5 years.

Early operation for aortic rupture has only rarely been attempted (see Table) and yet a review of 275 cases (Parmley

* From the Department of Thoracic Surgery, St. Mary's Hospital, London. ¥Recipient of an award from the British Heart Foundation. et al., 1958) revealed 38 patients (14\%) with proved traumatic aortic rupture who survived long enough to reach a hospital, only to die from haemorrhage within the next three weeks, although 31 of these survived for more than 12 hours. Five of the remaining seven died from rupture of the aneurysm in less than a year, and two patients survived after replacement of the aneurysm by a graft. Early survival depends on a compact haematoma and the strength of the remaining adventitia and adjacent pleura. Thus it may be assumed that a considerable proportion of patients could be saved by prompt diagnosis and immediate surgery.

\begin{tabular}{|c|c|c|c|c|c|}
\hline Year & Author & $\begin{array}{l}\text { Time of } \\
\text { Repair } \\
\text { After } \\
\text { Trauma }\end{array}$ & $\begin{array}{c}\text { Local } \\
\text { Pathology }\end{array}$ & Protection & Technique \\
\hline 1959 & Passaro and Pace & $18 \mathrm{hrs}$. & Small & & Suture \\
\hline 1964 & Dobell et al. & $39 \mathrm{hrs}$. & $\begin{array}{l}\text { Adventitia } \\
\text { intact }\end{array}$ & $\begin{array}{c}\text { Atriofemoral } \\
\text { bypass }\end{array}$ & Graft \\
\hline $\begin{array}{l}1964 \\
”\end{array}$ & $\begin{array}{c}\text { Fleischaker et al. } \\
" \#, "\end{array}$ & $\begin{array}{l}23 \text { hrs. } \\
14 \text { days }\end{array}$ & $\begin{array}{l}\text { Transection } \\
\text { Adventitia } \\
\text { intact }\end{array}$ & Hypothermia & " \\
\hline 1964 & Stoney et al. & $64 \mathrm{hrs}$. & Transection & $\begin{array}{l}\text { Atriofemoral } \\
\text { bypass }\end{array}$ & $\begin{array}{l}\text { End-to-end } \\
\text { anasto- }\end{array}$ \\
\hline 1964 & Jahnke et al. & 4 days & $\begin{array}{c}\text { Adventitia } \\
\text { intact }\end{array}$ & " & Graft \\
\hline " & " & 22 hrs. & Transection & \multirow{3}{*}{$\begin{array}{l}\text { Total cardio- } \\
\text { pulmonary } \\
\text { bypass + } \\
\text { hypothermia } \\
\text { Atriofemoral } \\
\text { bypass }\end{array}$} & و" \\
\hline " & " & 16 days & $\begin{array}{l}\text { Avulsion of } \\
\text { innominate } \\
\text { artery }\end{array}$ & & פ \\
\hline " & " & & Transection & & و \\
\hline " & " & $\begin{array}{l}6 \text { days } \\
7 \text { days }\end{array}$ & $\begin{array}{l}\text { Avulsion of } \\
\text { innominate }\end{array}$ & None " & $\begin{array}{c}\text { Direct } \\
\text { suture }\end{array}$ \\
\hline 1964 & McKnight et al. & 12 hrs. & $\begin{array}{l}\text { artery } \\
\text { Adventitia }\end{array}$ & $\begin{array}{l}\text { Atriofemoral } \\
\text { bypass }\end{array}$ & Graft \\
\hline 1965 & Bromley" et al. & $\begin{array}{c}24 \text { hrs. } \\
4 \text { hrs. }\end{array}$ & Transection & " & $\begin{array}{l}\text { End-to-end } \\
\text { anasto- } \\
\text { mosis }\end{array}$ \\
\hline
\end{tabular}

The present report describes the successful repair of a ruptured aorta four hours after injury, the earliest known case.

\section{Case History}

A 17-year-old boy was admitted to the casualty department of King Edward Memorial Hospital, Ealing, within 30 minutes of a road accident at 22.00 hours on 20 October 1964. Although he was unable to give a history at the time, he later described riding a motor scooter at 30-35 m.p.h. (48-56 km.p.h.) when the front wheel became stuck in the gutter; after several attempts to get the wheel out he fell, striking his chest against a lamp-post.

On admission he complained of difficulty in breathing, pain around both sides of the upper chest, tingling in both legs, and pain in the left thigh. He was pale, with marked venospasm and slight peripheral cyanosis. The radial pulses could not be felt, but the carotid and femoral pulses were palpable and the pulse rate was $140 / \mathrm{min}$. ; the blood-pressure was unrecordable. There was no head injury and there were no abnormal neurological signs. Respirations were shallow at $30 / \mathrm{min}$.; the trachea was central and air entry over both lungs was normal. No external marks were present on the chest and no evidence of rib or sternal injury was seen. There was marked guarding in the epigastrium but no pain or tenderness. Bowel sounds were heard. An abrasion on the front of the left thigh and a haematoma of the underlying quadriceps muscle were present. 
He was given $500 \mathrm{ml}$. of plasma intravenously in five minutes, and with this the pulse rate fell to $120 / \mathrm{min}$.; the radial pulses returned and the blood-pressure was recorded at 90/50 mm. Hg. A further $500 \mathrm{ml}$. of plasma was given, and 30 minutes after admission the pulse was $100 / \mathrm{min}$. and the blood-pressure $100 / 60$ mm. Hg. A chest $x$-ray examination at this time (Fig. 1) showed an opacity below and to the left of the aortic knuckle. The left chest was slightly more opaque than the right. Skeletal survey revealed no fractures. A film of the thoracic spine (Fig. 2) confirmed a localized mass in the upper left mediastinum. A provisional diagnosis of rupture of the thoracic aorta with left haemothorax was made as the findings were identical with those of a case previously seen which was not diagnosed until post-mortem examination (Bowen and Teare, 1962, addendum). At this stage the patient's condition had deteriorated again, and the pulse was $140 / \mathrm{min}$. and blood-pressure $90 / 50 \mathrm{~mm}$. $\mathrm{Hg}$ : a third $500 \mathrm{ml}$. of plasma and $600 \mathrm{ml}$. of whole blood were given, and the pulse rate fell to $110 / \mathrm{min}$. and the blood-pressure rose to $100 / 60 \mathrm{~mm}$. $\mathrm{Hg}$. The patient was then transferred to the thoracic unit at St. Mary's Hospital. A second $600 \mathrm{ml}$. of blood was given during this journey and a third bottle begun.

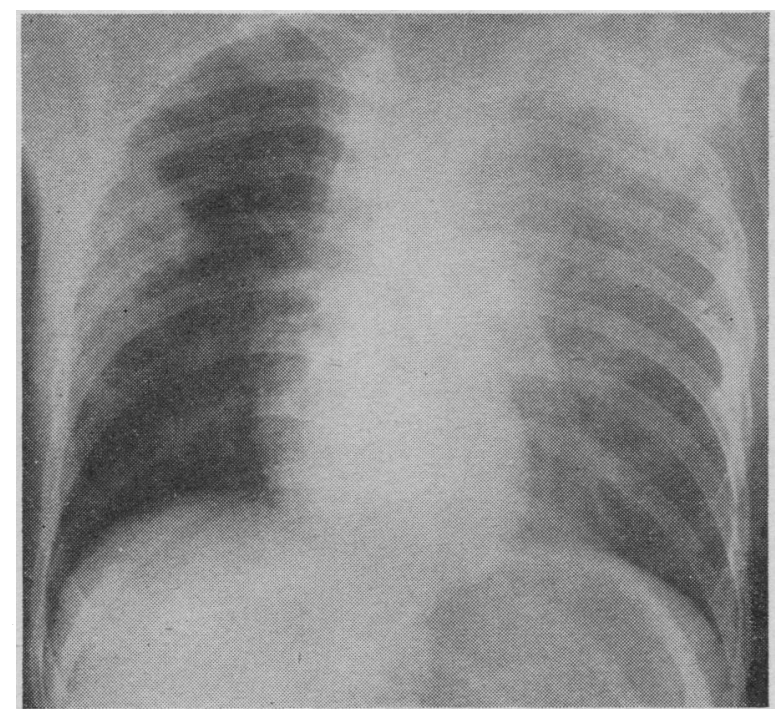

FIG. 1.-Chest $x$-ray film on admission, less than one hour after trauma, showing mediastinal mass in upper thorax.

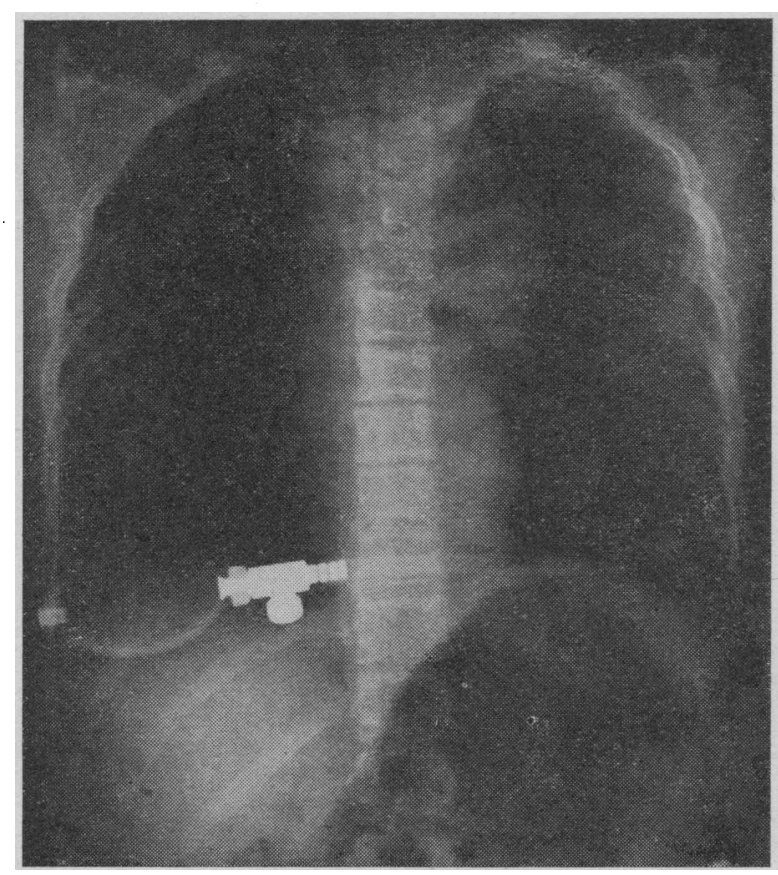

Fig. 2.-Penetrating $x$-ray film, taken to show thoracic spine, and defining upper mediastinal mass more clearly. Note gastric dilatation.
On arrival at St. Mary's Hospital three hours after his accident the patient was anxious and pale; the pulse rate was $98 / \mathrm{min}$. and blood-pressure $140 / 80 \mathrm{~mm}$. $\mathrm{Hg}$; the trachea was slightly deviated to the right and clinically there was a left-sided pleural effusion. The upper abdomen was tender and there was marked guarding. A chest $x$-ray film at this time (Fig. 3) showed gross widening of the mediastinum and opacity of the left chest. There was now an opaque area peripherally in the mid-zone of the right lung. Traumatic rupture of the descending thoracic aorta was thought to be almost certain and immediate operation was undertaken four hours after injury.

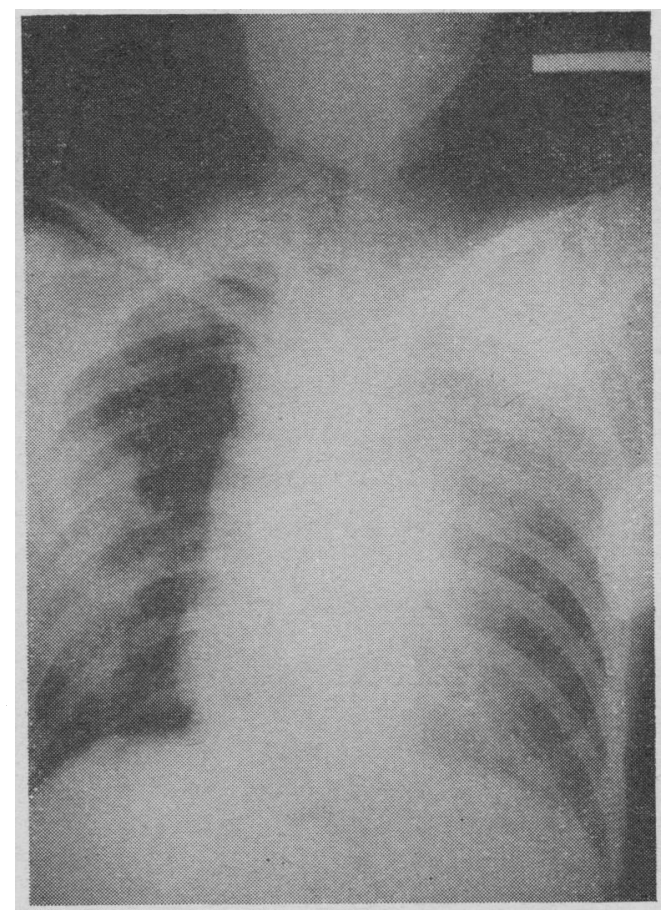

Fig. 3.-Chest $x$-ray film taken three hours after trauma, showing mediastinal widening and left haemothorax. Tid-zone of the right lung.

The patient was anaesthetized and placed in the lateral position, the left chest being opened through the fifth interspace; simultaneously the left femoral artery was exposed and prepared for cannulation. The left pleural space contained $400 \mathrm{ml}$. of unclotted blood and there was a massive haematoma of the mediastinum extending from the apex of the chest almost to the diaphragm. The haematoma extended proximally to the pericardium, and its mass was largest just below the origin of the left subclavian artery.

The pericardium was opened and a 5/16-in. (8-mm.) cannula was inserted into the left atrium via the appendage and a $4.5-\mathrm{mm}$. cannula was placed in the left femoral artery ; after heparinization of the patient, partial left heart by-pass was started at a flow rate of $1,500-2,000 \mathrm{ml} . / \mathrm{min}$. The parietal pleura was then incised along the posterior mediastinum, the aorta in the region of the reft subclavian artery was partially mobilized as well as the aorta near the lower limit of the haematoma. A transverse rupture of the aorta was found $3 \mathrm{~cm}$. below the origin of the left subclavian artery and $2 \mathrm{~cm}$. below the point of insertion of the ligamentum arteriosum. Initially this was palpable as a wide separation of the intima and media, but a few moments later the adventitia separated completely, with massive haemorrhage. This was rapidly controlled by clamping the two ends of the aorta, but the loss of blood during this manœuvre was $1,000 \mathrm{ml}$. The partial left heart by-pass was now reduced to $750 \mathrm{ml} . / \mathrm{min}$., and this flow rate maintained a satisfactory tension in the distal aorta, the proximal aortic pressure being $100 \mathrm{~mm}$. $\mathrm{Hg}$.

The mediastinal haematoma was then evacuated to expose clearly the ruptured ends of the aorta ; these were brought together and an end-to-end anastomosis was made without difficulty, trimming of the ends being unnecessary. By-pass was stopped after 50 minutes and protamine sulphate given to reverse the heparin after removal of the cannulae. 
The post-operative course was uneventful except for the development of a hyperdynamic hypertensive state on the third day. This was not fully explained as due to acidosis from retained bronchial secretions, but the blood-pressure fell after bronchoscopic aspiration and the administration of Arfonad (trimetaphan camphorsulphonate) intravenously. The patient was discharged on the 28th postoperative day and was symptom-free when he returned to work 10 weeks after the injury.

\section{Discussion}

Traumatic aortic rupture is to be suspected in a patient who complains of chest pain and shortness of breath after a deceleration injury. Physical examination and chest $x$-ray examination confirm the diagnosis; a penetrating chest $x$-ray film defines the aorta and the shadow due to the mediastinal haematoma more clearly (Fig. 2). The extravasation of blood into the mediastinal tissues in cases of leaking dissecting aortic aneurysms has been described as "arcuate excrescences" (Wood et al., 1932) and as "knobbly irregularities" (Levene et' al., 1954). Logue (1943) described the wide smooth mediastinal shadow of haemorrhage occurring together with pleural effusion as being characteristic of aortic rupture. The localized paraortic knuckle is demonstrated in Fig. 2, and typical widening of the mediastinal shadow, a constant finding on chest $x$-ray films, is shown in Fig. 1 ; the left-sided pleural effusion is most pronounced in the third chest $x$-ray film (Fig. 3), taken three hours after injury.

Although the clinical findings in traumatic aortic rupture may be insignificant because there is no evidence of external chest injury, the lesion must be recognized because most victims will soon die unless early operation is undertaken.

Thus the diagnosis should be made as early as possible because of the progressive nature of the lesion and the need for organizing emergency operative repair, by means of partial left heart bypass or, if this is not available, by a temporary shunt between the left subclavian artery and the femoral artery. The by-pass should be established before the false sac of the mediastinal haematoma is explored. In addition to saving more lives, surgical correction during the first 24 hours allows the aorta to be repaired by direct suture; the advantages of direct end-to-end suture of the aorta have been demonstrated by Alley et al. (1961). In the cases reported by Jahnke et al. (1964), in which surgery was delayed for several days, it was necessary to use a graft of foreign material because the vessel ends were too firmly fixed by organizing haematoma. McKnight et al. (1964), in two cases repaired at 12 and 24 hours respectively, chose to use Teflon grafts so as to avoid the possible occurrence of medial dissection; however, this is not seen as a complication when coarctation of the aorta is excised and continuity restored by direct end-to-end suture.

Although some authors have suggested aortography where aortic rupture is suspected, it is felt that this is indicated more for the late aneurysm, as valuable time may be lost during initial treatment: the developing clinical picture as illustrated by this patient made a diagnosis possible without using special radiological techniques.

\section{Summary}

A 17-year-old boy was admitted to hospital after a road accident in which he sustained a severe blow on the chest. Traumatic rupture of the thoracic aorta was diagnosed on clinical and radiological signs. Operative repair was undertaken four hours after the injury ; this early surgical repair resulted in a successful outcome, the patient returning to work 10 weeks after the accident.

\section{REFERENCES}

Alley, R. D., Van Meirop, L. H. S., Li, E. Y., Kausel, H. W., and R. D., Van Meirop, L. H. S., Li, E.

Bowen, D. A. L., and Teare, R. D. (1962). Thorax, 17, 150.

Dobell, A. R. C., MacNaughton, E. A., and Crutchlow, E. F. (1964). New Engl. f. Med., 270, 410 .

Eiseman, B., and Rainer, W. G. (1958). f. thorac. Surg., 35, 347.

Fleischaker, R. J., Mazur, J. H., and Baisch, B. F. (1964). F. thorac. cardiovasc. Surg., 47, 289.

Jahnke, E. J., Fisher, G. W., and Jones, R. C. (1964). Ibid., 48, 63.

Levene, G., Burke, E. N., and Arnois, D. C. (1954). Amer. F. Roentgenol., 72, 1004 .

Logue, R.' B. (1943). Amer. F. med. Sci., 206, 54.

Logue, R. B. (1943). Amer. F. med. Sci., 206, 54. 1 . Surney, R. P., and Vaughan, R. H. (1961). 670.

McKnight, J. T., Meyer, J. A., and Neville, J. F. (1964). Ibid., 160, 1069 .

Parmley, L. F., Mattingly, T. W., Manion, W. C., and Jahnke, E. J., jun. (1958). Circulation, 17, 1086.

Passaro, E., and Pace, W. G. (1959). Surgery, 46, 787.

Spencer, F. C., Guerin, P. F., Blake, H. A., and Bahnson, H. T. (1961). 7. thorac. cardiovasc. Surg. 41,1

Stoney, R. J., Roe, B. B., and Redington, J. V. (1964). Arch. Surg., 89, 840 .

Strassmann, G. (1947). Amer. Heart f., 33, 508

Wood, F. C.., Pendergrass, E. P., and Östrum, H. W. (1932). Amer. F. Roentgenol., 28, 437.

Brit. med. F., 1965, 2, 19-23

This report gives the results of a histological study of the blood-vessels of the skin of the leg; amputated limbs and skin biopsies were examined and the findings were then correlated with the results of previous clinical assessment.

Lesions of the feet occur much more commonly in diabetics than in non-diabetics. Bell (1957), in a necropsy series of 52,062 cases, found that the incidence of gangrene was increased 53 times in male diabetics and 71 times in females.

It used to be assumed that the cause was a greater liability

* Senior Registrar, Department of Surgery, Victoria Infirmary, Glasgow (presently Consultant Surgeon, Southern Ayrshire Hospitals).

t Registrar, Department of Pathology, Victoria Infirmary, Glasgow. to develop atherosclerosis plus a lowered resistance to infection. However, Oakley, Catterall, and Martin (1956) emphasized the importance of neuropathy ; they felt that most lesions of the feet in diabetics could be explained by a superimposition of neuropathy on the degree of arterial disease common to non-diabetics of the same age and sex.

Nevertheless, occasionally one sees diabetics with gangrene who show little clinical evidence of neuropathy or widespread sepsis, and who have a good blood supply as judged by the presence of a palpable pulse at ankle level. The question arises whether in diabetes there is a specific obliterative lesion of small distal blood-vessels. 